\title{
EDITORIAL
}

\section{Chronic obstructive pulmonary disease in 2025: where are we headed?}

\author{
D. Mannino
}

$\mathbf{T}$ he last 100 years have seen dramatic changes in the diseases that affect mankind, especially in the developed world. In the USA in 1900, infections were the leading causes of death, and mean life expectancy at birth was 49.2 yrs [1]. By 2000, heart disease was now the leading killer in the USA and life expectancy had increased to 76.5 yrs [1].

Chronic diseases became the leading killer in the USA in the 1960s. Over the next 40 yrs the age-adjusted mortality rate for heart disease, stroke and cancers steadily decreased, whereas the mortality rate for chronic obstructive pulmonary disease (COPD) steadily increased $[2,3]$. There are a variety of reasons for this, although the history of the smoking epidemic with uptake by males in the first two decades of the century followed by uptake by females in the middle part of the century, explains some of this [4]. Another phenomenon was, paradoxically, decreasing rates of smoking subsequent to the 1964 publication of the USA Surgeon General's report. The benefits for smoking cessation are more acute for cardiac disease, yet the lung damage done by smoking can exist for many years. Thus, many people who probably did not die from cardiac disease survived to develop and die from lung disease.

In the USA in recent years, prevalence, morbidity and mortality from COPD have continued to increase [5]. In 2000, more females than males in the USA died from COPD, although the age-adjusted rate was still lower among females.

The article in this issue of the European Respiratory Journal by HOOGENDOORN et al. [6] attempts to predict COPD trends in the Netherlands over the next 20 yrs. Their models begin with "diagnosed COPD" determined using administrative data. They were developed using data from several studies to determine the distribution of COPD severity, lung function decline, death and smoking cessation. They have predicted large increases in the prevalence of COPD at all levels of severity, along with related increases in COPD-related costs.

How likely is it that these predictions will come true? COPD is underdiagnosed in the USA and, in all likelihood, in other countries as well [7]. Thus, efforts to increase detection of disease may result in a higher burden of disease. Conversely, international efforts to decrease smoking may change the disease burden. Finally, ongoing efforts to change the natural history of COPD may result in decreased morbidity and improved survival $[8,9]$.

CORRESPONDENCE: D. Mannino, Pulmonary and Critical Care Medicine, University of Kentucky, 800 Rose Street, MN 614, Lexington, KY 40536, USA. Fax: 1 8592572418. E-mail: dmannino@uky.edu
So, where is chronic obstructive pulmonary disease headed in 2025? I suspect that disease prevalence will continue to increase in both the developed and developing world. I also believe that new treatment options will improve disease morbidity and quality of life. Of course, changes in the management of comorbid diseases associated with chronic obstructive pulmonary disease may also influence chronic obstructive pulmonary disease-related outcomes. Predicting the future is always challenging, and the predictions are frequently wrong. For chronic obstructive pulmonary disease, we'll just have to wait and see.

\section{REFERENCES}

1 Guyer B, Freedman MA, Strobino DM, Sondik EJ. Annual summary of vital statistics: trends in the health of Americans during the 20th century. Pediatrics 2000; 106: 1307-1317.

2 Decline in deaths from heart disease and stroke-United States, 1900-1999. MMWR Morb Mortal Wkly Rep 1999; 48: 649-656.

3 Pauwels RA, Buist AS, Calverley PM, Jenkins CR, Hurd SS. Global strategy for the diagnosis, management, and prevention of chronic obstructive pulmonary disease. NHLBI/WHO Global Initiative for Chronic Obstructive Lung Disease (GOLD) workshop summary. Am J Respir Crit Care Med 2001; 163: 1256-1276.

4 Tobacco use-United States, 1900-1999. MMWR Morb Mortal Wkly Rep 1999; 48: 986-993.

5 Mannino DM, Homa DM, Akinbami LJ, Ford ES, Redd SC. Chronic obstructive pulmonary disease surveillanceUnited States, 1971-2000. MMWR Surveill Summ 2002; 51: $1-16$.

6 Hoogendoorn M, Rutten-van Mölken MPMH, Hoogenveen RT, et al. A dynamic population model of disease progression in COPD. Eur Respir J 2005; 26: 223-233.

7 Mannino DM, Gagnon RC, Petty TL, Lydick E. Obstructive lung disease and low lung function in adults in the United States: data from the National Health and Nutrition Examination Survey, 1988-1994. Arch Intern Med 2000; 160: 1683-1689.

8 Fishman A, Martinez F, Naunheim K, et al. A randomized trial comparing lung-volume-reduction surgery with medical therapy for severe emphysema. N Engl J Med 2003; 348: 2059-2073.

9 Vestbo J. The TORCH (towards a revolution in COPD health) survival study protocol. Eur Respir J 2004; 24 206-210. 